Open Access

\title{
Off-label use of targeted therapies in osteosarcomas: data from the French registry OUTC'S (Observatoire de I'Utilisation des Thérapies Ciblées dans les Sarcomes)
}

Mathilde Penel-Page ${ }^{1,2^{*}}$, Isabelle Ray-Coquard ${ }^{1,2}$, Julie Larcade ${ }^{1,2}$, Magali Girodet ${ }^{1}$, Laure Bouclier ${ }^{1}$, Muriel Rogasik ${ }^{1}$, Nadège Corradini ${ }^{3}$, Natacha Entz-Werle ${ }^{4}$, Laurence Brugieres ${ }^{5}$, Julien Domont ${ }^{5}$, Cyril Lervat $^{6}$, Sophie Piperno-Neumann ${ }^{7}$, Helène Pacquement ${ }^{7}$, Jacques-Olivier Bay ${ }^{8}$, Jean-Claude Gentet ${ }^{9}$, Antoine Thyss ${ }^{10}$, Loic Chaigneau ${ }^{11}$, Bérangère Narciso ${ }^{12}$, Helène Cornille ${ }^{13}$, Jean-Yves Blay ${ }^{1,2}$ and Perrine Marec-Bérard ${ }^{1,2}$

\begin{abstract}
Background: The objective of this study is to explore the off-label use of targeted therapies (TTs) for patients with osteosarcoma registered within the French Sarcoma Group - Bone Tumor Study Group (GSF-GETO) national registry.

Methods: All patients with an osteosarcoma, registered between January 1, 2009 and July 15, 2013 were analyzed. Results: Twenty-nine patients with refractory relapsed osteosarcomas received 33 treatment lines of $\Pi s$. The median age at the beginning of treatment was 19 years (range 9-72). The median number of previous lines of chemotherapy was 3 (range 1-8). Before inclusion, 3 patients were in second complete remission, 26 were in progression for metastatic relapse. Twenty-three patients received sirolimus (in combination with cyclophosphamide for 18); 5, sunitinib; 4, sorafenib; and one, pazopanib. Stable disease was observed for $45.5 \%$ of patients (95\% Confidence Interval (CI) [20-52.8]). The median Progression-Free Survival (PFS) was 3 months (95\% $\mathrm{Cl}$ [2-5.4]) for patients treated by sirolimus and 1.8 months (95\% Cl [1.3-2.8]) for patients receiving multi-targeted tyrosine kinase inhibitors; 6-month PFS $15 \%$. The median Overall Survival (OS) was 6.8 months (95 \% Cl [4.7-12.1]), and one-year OS was $24 \%$. In a multivariate analysis, PFS was superior for patients receiving sirolimus compared to other Ts (Hazard Ratio $(H R)=2.7,95 \% \mathrm{Cl}$ [1.05-7.1]). No toxic death was reported. Grade 3 and 4 toxicities were observed in 27 and $6 \%$ of cases respectively.
\end{abstract}

Conclusion: Off-label $\Pi s$, especially sirolimus, reported benefit in the treatment of refractory osteosarcomas with an acceptable toxicity profile, including in pediatric population.

Keywords: Targeted therapy, Tyrosine-kinase inhibitors, Off-label, mTOR inhibitors, Bone sarcoma, Osteosarcoma, Relapse, Maintenance therapy

\footnotetext{
* Correspondence: p.mathilde@free.fr

${ }^{1}$ Department of Pediatric Oncology, Léon Bérard Cancer Center, 28, rue

Laennec, 69008 Lyon, France

2Université Claude Bernard Lyon 1, Lyon, France

Full list of author information is available at the end of the article
}

\section{Biomed Central}

(c) 2015 Penel-Page et al. Open Access This article is distributed under the terms of the Creative Commons Attribution 4.0 International License (http://creativecommons.org/licenses/by/4.0/), which permits unrestricted use, distribution, and reproduction in any medium, provided you give appropriate credit to the original author(s) and the source, provide a link to the Creative Commons license, and indicate if changes were made. The Creative Commons Public Domain Dedication waiver (http://creativecommons.org/publicdomain/zero/1.0/) applies to the data made available in this article, unless otherwise stated. 


\section{Background}

High-grade osteosarcoma is the most common malignant bone tumor in adolescents and young adults [1]. Multimodal treatment including chemotherapy and radical surgery increased the Progression-Free-Survival (PFS) from 10 to $65 \%$ [2]. However, we still observe $30 \%$ of relapse, mainly with metastatic stage, with less than $20 \%$ long-term survival for these patients [3].

The role of chemotherapy in recurrent osteosarcomas is not fully established [4]. There is no standard regimen recommended for second-line treatment $[1,5]$. Except for muramyl tripeptide (L-MTP-PE) which demonstrated an improvement of median time to relapse from 4,5 months to 9 months in a phase II trial [6], recently tested drugs (etoposide, carboplatine, gemcitabine, high dose chemotherapy [7], ecteinascidin [8], samarium [9]) failed to improve long-term survival of these patients [10,11].

Several biological pathways are implicated in bone sarcomas and represent a potential interesting approach for the treatment of such tumors with targeted therapies (TTs) : sustaining proliferative signal (IGFR, SHH/GLI, PDGFR, c-KIT), evading cell growth suppressors (p53, RB, CDK), resisting to cell death (ERK activation, proapoptotic molecule inhibition, antiapoptotic molecule activation $\mathrm{Bcl} 2$, syndecan-2), enabling replicative immortality, increasing angiogenesis (VEGFR, IGFR, PDGFR, HIF1 $\alpha$ ) and activating invasion and metastasis, genome instability (p53, GADD45), evading immune destruction (IFN), or interacting with the bone microenvironment (RANK/ RANKL/OPG) [12]. Unfortunately, the rarity of these pathologies and the specificity of the pediatric population don't hold pharma industries nor governments to delineate phase III trials and prove the benefit of such compounds for refractory osteosarcomas.

In 2008, the GSF-GETO established a National Observatory for The off-label Use Of Targeted Therapies in Sarcomas (OUTC'S) as a resource for the research into the use of TTs in routine practice. All medical data regarding the use of off-label TTs in sarcomas was collected in a prospective way to analyze activity and toxicity of TTs in these tumors [13]. This report aims to describe the utilization, efficacy, and safety data on osteosarcoma patients registered in OUTC'S in order to identify TTs which warrant further investigations in this pathology.

\section{Methods}

\section{Patients/Registry}

Patients who met the following criteria were included: osteosarcoma upon histological diagnosis, no age-limit, not amenable to curative treatment or inclusion in clinical trial, treatment in France. They received an information letter. Oral consent for data collection and use for research purpose was requested before inclusion.
Children could be included with parents' oral consent. As reported previously, all details of the methodology was anticipated. Once a patient registered, he was evaluated by his referring doctor and a follow-up file was sent every two months to the coordination center.

\section{Competent authorities approval}

All data was collected by the coordination center (Centre Léon Bérard, Lyon) upon approval of the local Clinical Trial Review Committee (CREC, Lyon, France), the French Consultative Committee for the Data Processing in Health Research (CCTIRS, Paris, France) and the French data protection authority (National Commission of Informatics and Liberty, Paris, France, declaration $\left.\mathrm{n}^{\circ} 1375805\right)$. Most decisions of treatment involving offlabel TT treatment were made during a Multidisciplinary Tumor Board (MTB), as defined by the French Sarcoma Network (NetSarc) [14].

\section{Data collection and study endpoints}

The primary objective was to describe the efficacy of offlabel TTs in osteosarcoma patients. Endpoints were response rate for each TT: rate of complete and partial remission (CR, PR) according to RECIST (Response Evaluation Criteria for Solid Tumors [15]), disease control rate (rate of CR, PR and stable disease as best response), Progression-Free-Survival (PFS), Overall Survival (OS) and duration of response. The secondary objective was the characterization of toxicities.

\section{Statistical methods}

PFS was calculated from the beginning of TT to the date of the event, defined as the first documented progression or death whatever the cause under treatment. Patients who did not experience an event were censored at the date of treatment discontinuation or at the date of last contact for patients still under treatment. OS was calculated from the beginning of treatment until the date of death whatever the cause, and censored at the date of last contact for patients alive. PFS and OS were estimated by the Kaplan Meier method with their $95 \%$ confidence interval (CI) and comparisons were done by a logrank test, in the XLstat software. Safety evaluation was based on the frequency and severity of toxicities graded according to the Common Terminology Criteria for Adverse Events [16].

Patients could be included in the Observatory for each consecutive line of TT. All analyses were performed on the total number of treatment lines, except for data regarding OS which was analyzed on the total number of patients included at least once in the study. Regarding patients included several times, OS was defined as the time between the first inclusion and date of the last follow up for the last treatment. The database was 
locked for statistical analysis in July 2013. This is a descriptive analysis.

\section{Results}

\section{Patient characteristics}

From September 2009 to July 2013, 29 patients from 12 centers (8 pediatric, 1 adult and 3 mixed) were registered and received 33 lines of TTs. Median age at the beginning of TTs was 19 (range 9 to 72) and median duration between the diagnosis of osteosarcoma and the beginning of a TTs was 2.7 years (range 7 months to 7 years). A median of 3 lines of chemotherapy (range 1-8) was administrated before starting TTs (Table 1 ).

\section{Off-label targeted therapies}

The decision of using off-label TTs was made in a MTB for 24 patients $(73 \%)$. There was no difference in the decision process between adults and pediatric units. Sirolimus was used for 23 patients (70 \%), mostly in combination with chemotherapy $(n=20)$. Multi-targeted Tyrosine Kinase Inhibitors (TKI) were used in 10 patients (Table 2). Doses and modalities of treatment were heterogeneous.

\section{Efficacy of targeted therapies Response to treatment}

Stabilization of the disease was observed in 15 patients (45.5\%, $95 \%$ CI [28.5-62.4]), with a median duration of stabilization of 4.8 months (range 1 to 17).

Among the 20 patients in progressive disease treated with sirolimus, 7 (35\%) were stabilized: 1 with sirolimus alone, 6 in combination. Two patients treated in CR were maintained 4.8, 12.9 months respectively. The third patient stopped treatment after 17 months of continuing CR.

Under sorafenib $(n=4)$, stabilization was observed for 3 patients. One clinical PR (not RECIST) and one stabilization were observed under sunitinib. The patient treated with pazopanib had rapid disease progression (Table 2).

\section{Follow up and survival}

The median follow-up time after diagnosis was 3 years (range 1.1 to 7.2). The median PFS for the whole group was 2.3 months (95\% CI [1.9-3.7]). The PFS was $61 \%$ at 2 months $(n=20), 30 \%$ at four months $(n=10), 15 \%$ at six months $(n=5)$ (Fig. 1).

The median PFS was 3 months (95 \% CI [2.2-5.4]) for patients treated by sirolimus (2.7 months in combination, 5.7 months alone) and 1.8 months (95\% CI [1.3-2.8]) for patients receiving TKI (Fig. 2). Six-month PFS was $22 \%$ for patients receiving sirolimus, and $0 \%$ for other TTs. In a multivariate analysis, the only factor significantly affecting the prognosis was the TT used: patients treated by
Table 1 Population characteristics

\begin{tabular}{|c|c|c|c|}
\hline Gender & & & \\
\hline & Male & 19 & $66 \%$ \\
\hline & Female & 10 & $33 \%$ \\
\hline \multicolumn{4}{|c|}{ Age at diagnosis } \\
\hline & & 18,1 & \\
\hline & median (min-max) & 19 & $8-65$ \\
\hline \multicolumn{4}{|c|}{$\begin{array}{l}\text { Age at initiation of } \\
\text { treatment }\end{array}$} \\
\hline & & 19 & \\
\hline & median (min-max) & 20 & $9-72$ \\
\hline & $\leq 18$ years & 15 & $45 \%$ \\
\hline \multicolumn{4}{|c|}{$\begin{array}{l}\text { Histological subtype of } \\
\text { osteosarcoma }\end{array}$} \\
\hline & osteoblastic & 18 & $62 \%$ \\
\hline & chondroblastic & 5 & $17 \%$ \\
\hline & osteogenic & 3 & $10 \%$ \\
\hline & telangiectasic & 2 & $7 \%$ \\
\hline & pleiomorphic & 1 & $4 \%$ \\
\hline
\end{tabular}

Tumor grade

Grade III $\quad 29 \quad 100 \%$

Stage at beginning of

$\begin{array}{lll}\text { progression } & 30 & 91 \% \\ \text { complete remission } & 3 & 9 \%\end{array}$

Localization of relapse

$\begin{array}{lll}\text { localized } & 0 & 0 \% \\ \text { metastatic } & 24 & 73 \% \\ \text { both } & 9 & 27 \%\end{array}$

Number of previous treatment lines

$\begin{array}{lll} & 2,9 & \\ \text { median (min-max) } & 3 & 1-8 \\ 0 & 0 & 0 \% \\ 1 & 4 & 12 \% \\ 2 & 12 & 36 \% \\ 3 & 10 & 30 \% \\ \geq 4 & 7 & 21 \%\end{array}$

Delay diagnosis initiation of TT

$\begin{array}{ll} & 2,8 \text { years } \\ \text { median (min-max) } & 2,7 \text { years } \quad(0,6-7 \text { years })\end{array}$

sirolimus had a better PFS, with a hazard ratio of 2.7 (95 \% CI [1.05-7.1]) (Table 3).

The median PFS was 2 months (95\% CI [0.8-9]) for 4 patients treated at first relapse, 2.3 months $(95 \% \mathrm{CI}$ [1.9-6.9]) for 12 patients experiencing a second relapse, 
Table 2 Duration of response

\begin{tabular}{llll}
\hline $\begin{array}{l}\text { Targeted } \\
\text { Therapy }\end{array}$ & $N=33$ & $\begin{array}{l}\text { Stable disease as } \\
\text { best response }\end{array}$ & $\begin{array}{l}\text { Median duration of } \\
\text { response (months) }\end{array}$ \\
\hline $\begin{array}{l}\text { Sirolimus } \\
\text { alone }\end{array}$ & 3 & 1 & 4,75 \\
$\begin{array}{l}\text { Sirolimus Cy } \\
13\end{array}$ & $\begin{array}{l}\text { 7 (3 maintained } \\
\text { complete } \\
\text { remission) }\end{array}$ & 5,4 \\
$\begin{array}{l}\text { Sirolimus Cy } \\
\text { Adriamycine }\end{array}$ & 1 & 1 & 6,2 \\
$\begin{array}{l}\text { Sirolimus Cy } \\
\text { Vinorelbine }\end{array}$ & 3 & 0 & \\
$\begin{array}{l}\text { Sirolimus Cy } \\
\text { Zolendronate }\end{array}$ & 1 & 1 & 9 \\
$\begin{array}{l}\text { Sirolimus } \\
\text { Irinotecan }\end{array}$ & 2 & 0 & 3,1 \\
Sorafenib & 4 & 3 & 3,4 \\
Sunitinib & 5 & 2 (1 PR) & \\
Pazopanib & 1 & 0 & 4,8 \\
Total & 33 & 15 &
\end{tabular}

Cy cyclophosphamide
3 months (95\% CI [1.3-4.7]) for 10 patients at third relapse, and 2.2 months (95\% CI [1.8-3.5]) for 7 patients at fourth (or more) relapse.

Five patients achieving 6-months PFS had received the combination sirolimus-cyclophosphamide. Their median age was 17 at the beginning of TTs. One patient experienced a first relapse while the others had a second, and two were in complete remission at the treatment initiation.

The median OS was 6.8 months (95\% CI [4.7-12.1]). OS at one year was $24 \%$ (30\% with sirolimus, $10 \%$ with TKI).

\section{Tolerance of treatment}

Treatment interruption occurred in 26 cases $(79 \%)$ due to disease progression and in 3 cases $(9 \%)$ due to death caused by cancer. Only one TT line was stopped for toxicities (grade 3 hematuric cystitis due to cyclophosphamide).

Among 33 lines of treatment, 22 (67\%) patients reported at least one adverse event (AE). Thirty-nine AEs were reported. Gastro-intestinal toxicity was observed in $27 \%$ of patients (nausea, vomiting, stomatitis), hematologic toxicity in $24 \%$ and fatigue in $24 \%$. Other AEs (skin, infection, headache, alopecia, depression) were reported in less than $10 \%$ of cases (Table 4 ).

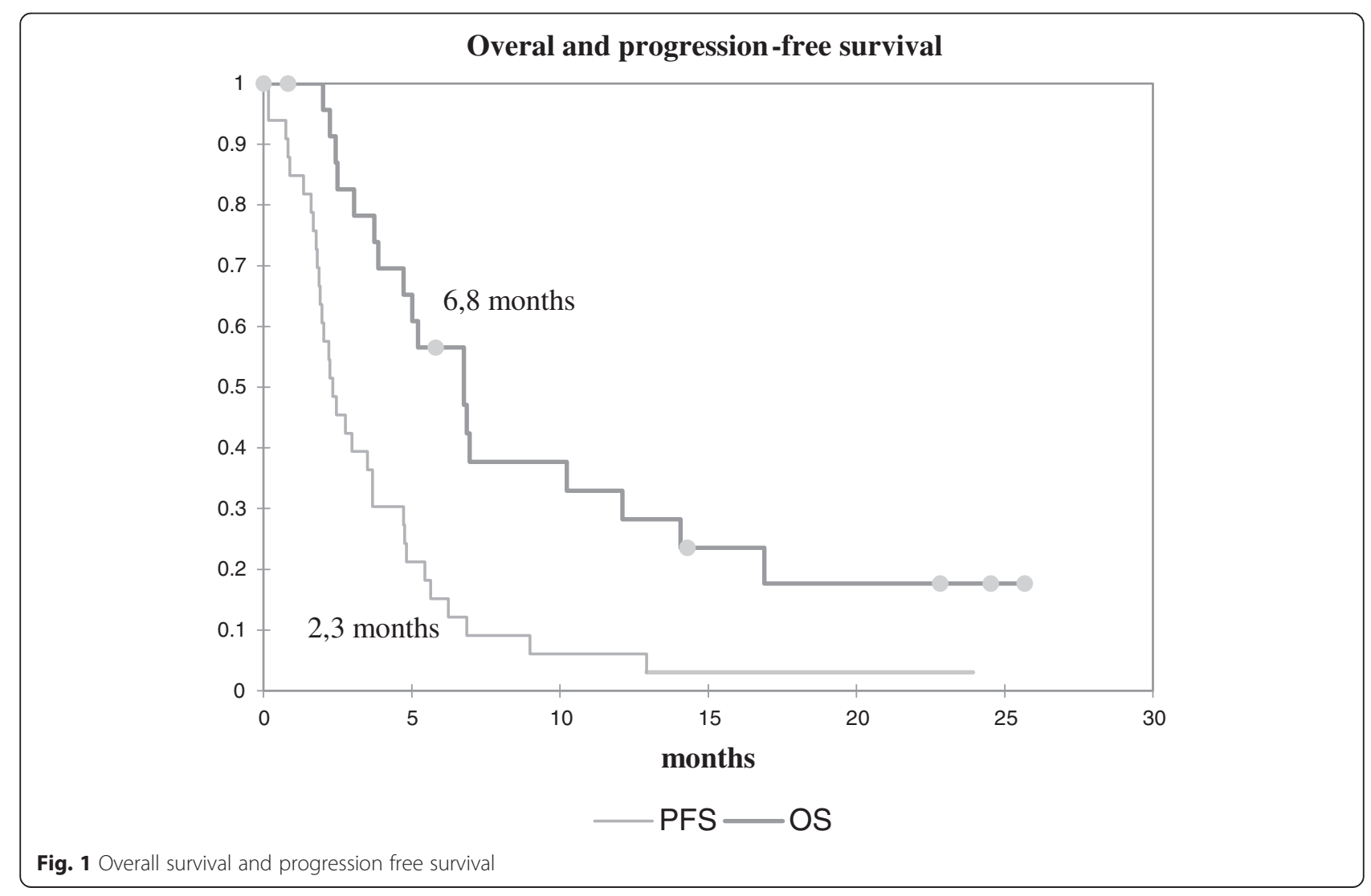




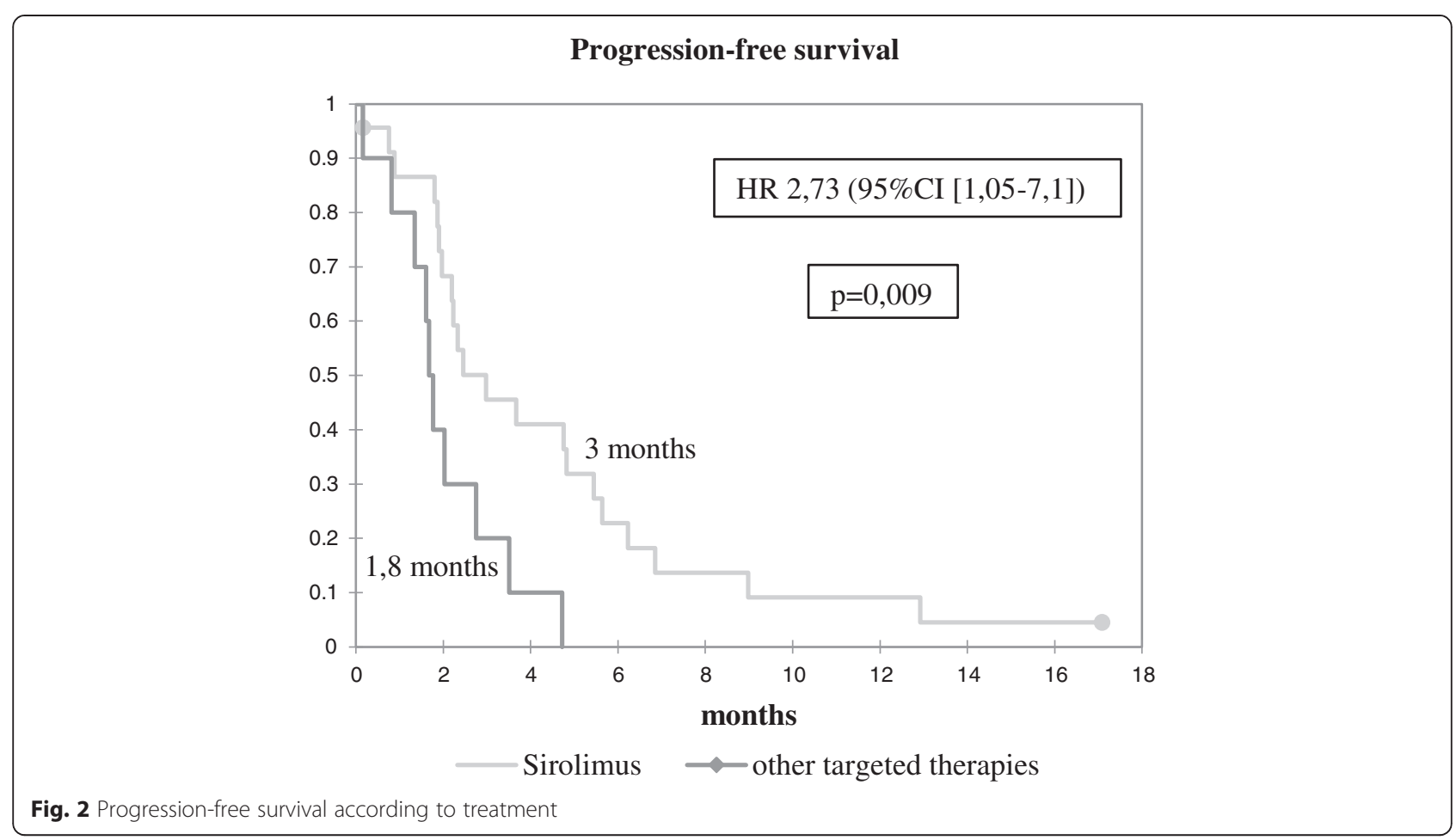

Most of AEs were grade 1-2 (72 \% of AEs). Hematologic, fatigue, and skin, grade 3, were observed for 9 patients (27\%). Grade 4 was hematologic and affected only 2 patients treated by sirolimus - cyclophosphamide vinorelbine or adriamycine. The median grade of toxicities with TKI was 2.3, and with sirolimus 1.7 .

Five TTs (15\%) were modified for toxicity (dose reduction or temporary interruption). No toxic death was reported.

\section{Discussion}

This study reported a $45.5 \%$ disease control rate with TTs used off-label in refractory relapsed osteosarcomas with a good tolerance profile. In a multivariate analysis, PFS seemed superior for patients receiving sirolimus compared to other TTs.

Many molecular abnormalities are identified in osteosarcomas giving the cancer cells some particular characteristics: proliferative signals (PDGFR, IGFR, c-KIT), resistance to retroaction signals $(\mathrm{p} 53, \mathrm{RB})$, resistance to cell death (ERK, Bcl-2), angiogenesis (VEGFR, PDGFR), resistance to immune destruction (IFN) [12]. Potential

Table 3 Multivariate analysis: factors influencing PFS

\begin{tabular}{llll}
\hline & Hazard Ratio & $95 \% \mathrm{Cl}$ & $p$ \\
\hline Delay before treatment & 1,00 & $0,99-1$ & 0,44 \\
$\leq 2$ previous treatment lines & 0,69 & $0,27-1,74$ & 0,43 \\
Histology : osteoblastic & 0,80 & $0,37-1,73$ & 0,57 \\
Treatment by Sirolimus & 2,73 & $1,05-7,1$ & 0,04 \\
\hline
\end{tabular}

TTs could either inhibit growth factor signaling pathways, or enhance apoptosis, or inhibit the metastatic process, or modulate the antitumor immune response, or modulate the bone microenvironment to increase local control of the primary tumor, limit metastatic spread, and finally improve patient survival [17].

mTOR is an intracellular protein, playing a major role in protein synthesis and influencing the cell growth, differentiation and apoptosis: this pathway is unregulated in many cancers, leading to the permanent activation, often under the influence of IGF1R. mTOR also plays a role in angiogenesis by controlling the production of HIF (Hypoxia Inducible Factor) [18]. Preclinical studies demonstrated that sirolimus, the main mTOR inhibitor, blocks the ezrin pathway implicated in the metastatic migration of osteosarcomas [19]. In 2012, a phase II study reported a clinical benefit in $28.8 \%$ of patients treated with ridaforolimus for a metastatic or inoperable sarcoma with an increased PFS compared to untreated patients [20]. Another phase II study testing the association of sirolimus and cyclophosphamide in soft tissue and bone sarcomas, highlighted a synergic effect of the two drugs, leading to an increased PFS with a good tolerance [21]. A double blind phase III maintenance trial comparing ridaforolimus and placebo in advanced sarcoma after stabilization or response with chemotherapy, enrolled 50 bone sarcoma patients showing a longer PFS and a $28 \%$ reduction in the risk of death or progression with the maintenance strategy [22]. This data constituted the rational for using mTor inhibitors in refractory 
Table 4 Adverse events

\begin{tabular}{|c|c|c|c|c|}
\hline & \multirow{2}{*}{$\begin{array}{l}\text { Total } \\
N(\%)\end{array}$} & \multicolumn{3}{|c|}{ Grade } \\
\hline & & 1 & 2 & $3-4$ \\
\hline \multicolumn{5}{|l|}{ Sirolimus $(n=23)$} \\
\hline At least 1 toxicity reported & $14(60)$ & & & \\
\hline Intestinal toxicity & $8(34)$ & 7 & 1 & \\
\hline Skin toxicity, infections & $1(4)$ & 1 & 1 & \\
\hline Hematologic toxicity & $6(26)$ & 1 & 1 & 4 \\
\hline Urinary toxicity & $1(4)$ & & & 1 \\
\hline Neurological toxicity & $3(13)$ & 2 & 1 & \\
\hline Other (fatigue, pain) & $6(26)$ & 4 & 2 & \\
\hline Dose modification & $2(9)$ & & & \\
\hline Discontinuation for toxicity & $1(4)$ & & & \\
\hline \multicolumn{5}{|l|}{ Sunitinib $(n=5)$} \\
\hline At least 1 toxicity reported & $4(80)$ & & & \\
\hline Hematologic toxicity & $2(40)$ & & 2 & \\
\hline Pulmonary toxicity & $1(20)$ & & & 1 \\
\hline Other (fatigue) & $2(40)$ & 2 & & 1 \\
\hline Dose modification & $1(20)$ & & & \\
\hline \multicolumn{5}{|l|}{ Sorafenib $(n=4)$} \\
\hline At least 1 toxicity reported & $3(75)$ & & & \\
\hline Skin toxicity, infections & $2(50)$ & & 1 & 1 \\
\hline other (fatigue, psychological) & $4(100)$ & & 1 & 2 \\
\hline Dose modification & $2(50)$ & & & \\
\hline \multicolumn{5}{|l|}{ Pazopanib $(n=1)$} \\
\hline At least 1 toxicity reported & 1 & & & \\
\hline Intestinal toxicity & 1 & & 1 & \\
\hline Other (fatigue) & 1 & & & 1 \\
\hline Dose modification & 0 & & & \\
\hline Total & $\geq 1$ AE: 22 & 17 & 11 & 11 \\
\hline
\end{tabular}

osteosarcomas, first in adults and recently in pediatric population (Table 5). Data provided by OUTC'S registry confirmed the value of this agent in osteosarcomas especially combined with conventional chemotherapy to prolong survival and time to progression in this particularly dismal prognosis group.

Sorafenib inhibits B-raf, c-KIT, PDGFR, VEGFR and RET. In osteosarcoma, sorafenib inhibits the proliferation of tumor, angiogenesis (VEGF), invasion (MMP2), the emergence of pulmonary metastases (Erzin/ $\beta 4$-integrin/ PI3K) and induces apoptosis [23]. This drug has already been approved for renal and hepatocarcinoma treatment and has shown good responses in angiosarcomas [24]. Yet, the use of sorafenib in osteosarcomas is mainly based on a phase II study, conducted in 35 patients with progression despite standard treatment and reporting 5 PRs, a clinical benefit rate of $29 \%$ and a four-month PFS of $46 \%$ [25].
Sunitinib inhibits FLT3, c-KIT, PDGFR and VEGF. Efficacy was observed with in vivo models, mostly pediatric tumors, including Ewing sarcoma xenografts [26]. Clinical benefit is reported for 4 patients with sarcomas in phase I [27] and 34 in phase II studies [28].

Pazopanib is mainly steered against VEGFR and PDGFR. A phase II study reported 9 cases of PR and improvement of OS and PFS for 143 patients with progressive soft tissue sarcoma [29]. A randomized double blind phase III study of pazopanib versus placebo, showed improved OS and PFS for a metastatic soft tissue sarcoma after failure of chemotherapy treatment [30]. A randomized double-blinded phase II is currently open to evaluate regorafenib, a promising TKI [31] in advanced bone sarcomas [32]. Based on this literature, TKI have been used off-label in adult refractory sarcoma first, thereafter by pediatricians influenced by adult practices despite the paucity of pharmacological data in pediatric population.

We report in this study only one objective response after initiation of TT. It has been suggested that the evaluation of TTs efficacy could not be done by RECIST compared to conventional treatments because TKI are mainly cytostatic. Some cases of cystic tumors after treatment by TKI have been reported [33]. Indeed, a stable disease induced by a TT could be considered as a satisfying response and a significant clinical benefit given the poor prognosis of metastatic refractory sarcomas. In order to guide the objectives of clinical trials, the EORTC Sarcoma Group (European Organization for Research and Treatment of Cancer) defined that a second-line treatment could be considered active if it showed a 6-month PFS of $40 \%$ and as inactive if it was below $20 \%$ [33]. In our study, six-month PFS was $15 \%$ ( $22 \%$ with sirolimus, $0 \%$ with TKI), but all patients included had very poor prognosis factors: inoperable tumor, high grade histology, treatment-line failures. Most published series about this population reported dismal prognosis, with short median survival especially after several relapses $[11,34]$. In this cohort, the oneyear OS of $24 \%$ and median survival of 6.8 months could be a significant result. The difference observed in median PFS between sirolimus group and TKI group (2.3 versus 1.8 months) encourages investigating this drug in a clinical trial.

Given the number of different mechanisms involved in carcinogenesis and treatment failures, a molecular study of each tumor could guide the indications of TTs and compounds. Some mechanisms lead to the cell resistance to Sirolimus, in particular because only the complex MTORC1 is sensitive to Sirolimus, whereas MTORC2 is resistant [17]. The activation of MTORC2 leads to treatment failure. This mechanism can be blocked by the association with Sorafenib: in vitro and 
Table 5 Studies reporting any benefit of $\Pi$ s for osteosarcoma patients

\begin{tabular}{|c|c|c|c|}
\hline \multicolumn{4}{|l|}{ mTOR inhibitors } \\
\hline Ridaforolimus in patients with advanced bone and soft tissue sarcomas & Chawla et al. & Phase ॥ & 2012 \\
\hline Sirolimus and Cyclophosphamide in patients with advanced sarcomas & Schuetze et al. & Phase II & 2012 \\
\hline $\begin{array}{l}\text { Ridaforolimus versus placebo to control metastatic sarcomas in patients } \\
\text { after benefit of prior chemotherapy (SUCCEED) }\end{array}$ & Demetri et al. & Phase III & 2013 \\
\hline \multicolumn{4}{|l|}{ TKI } \\
\hline Sorafenib blocks tumour growth, angiogenesis and metastatic potential & Pignochino et al. & preclinical & 2009 \\
\hline Sorafenib in patients with metastatic or recurrent sarcomas & Maki et al. & Phase II & 2009 \\
\hline $\begin{array}{l}\text { Sorafenib in relapsed and unresectable high-grade osteosarcoma after } \\
\text { failure of tandard multimodal therapy: an Italian Sarcoma Group Study }\end{array}$ & Grignani et al. & Phase II & 2012 \\
\hline Initial testing of sunitinib by the pediatric preclinical testing program & Maris et al. & Phase I & 2008 \\
\hline $\begin{array}{l}\text { Sunitinib in pediatric patients with refractory solid tumors: a Children's } \\
\text { Oncology Group study }\end{array}$ & Dubois et al. & Phase I & 2011 \\
\hline Sunitinib in patients with relapsed or refractory soft tissue sarcomas & Tariq Mahmood et al. & Phase II & 2011 \\
\hline Pazopanib for metastatic soft-tissue sarcoma (PALETTE) & Van der Graaf et al. & Phase III & 2012 \\
\hline Pazopanib in patients with relapsed or refractory advanced soft-tissue sarcoma & Sleijfer et al. & Phase II & 2009 \\
\hline
\end{tabular}

in vivo, the combination of the two drugs increases the anti-tumor, anti-angiogenic and anti-metastatic activity [35]. Despite this data, no combination of TKI with mTOR inhibitor was reported in OUTC'S: it could be worth exploring this strategy.

In this study, tumor control lasted more than 6 months for 5 patients. These patients had a median age of 17 at the TT initiation, which is below the median age of the whole group and compatible with data showing a better response to chemotherapy in children [36]. All these patients received sirolimus in association with cyclophosphamide. One patient was treated at first relapse and the others at second relapse, suggesting that efficiency of sirolimus could be optimized when used with minimal tumoral disease.

We must underscore that three patients received a maintenance treatment combining sirolimus-cyclophosphamide, after complete remission by surgery and chemotherapy. This strategy is developing in sarcomas, supported by studies suggesting that it could improve survival and decrease the risk of relapse in high-risk patients $[22,37]$ and must be confirmed in randomized clinical trial dedicated to maintenance therapy including PFS, OS and quality of life.

Observed data of toxicity are similar to what was already described in clinical trials [13]. No major toxic effect has been reported and only one patient had to stop TTs because of toxicity, showing that tolerance to TTs is acceptable, even in children.

The main limitation of this study is the small number of patients, due to the rarity of these tumors, which can reduce the statistical power, in particular for the comparison between TKI and sirolimus (since the CI of the hazard ratio approximates 1). The specificities of pediatric population make it difficult to launch clinical trials assessing efficacy of TTs in osteosarcomas. Registering patient in a national database like OUTC'S is an opportunity to obtain more information about safety and efficacy of drugs used off-label with a rational based on published data.

\section{Conclusion}

Targeted therapies could play a part in the treatment of refractory osteosarcomas or in maintenance for patients with a high risk of relapse. Tolerance is acceptable, even for patients under 18. This data suggests that sirolimus could have an interesting anti-tumor activity in osteosarcomas and deserves to be evaluated in a prospective trial, either alone or in combination with chemotherapy.

\section{Abbreviations}

AE: adverse events; CDK: Cyclin dependent kinase; C-KIT: v-kit HardyZuckerman 4 feline sarcoma viral oncogene homolog; CNIL: Commission national de l'informatique et des libertés; CR: complete response; EORTC: European Organization for Research and Treatment of Cancer; ERK: extracellular signal-regulated kinase; FLT3: Fms-like tyrosine kinase 3; GADD45: Growth arrest and DNA damage-inductible 45 protein; GSFGETO: French sarcoma group, Group for the study of bone tumors; HIF1: Hypoxia inductible factor; IC: confidence interval; IFN: Interferon; IGFR: Insulin-like growth factor receptor; MMP2: matrix metallopeptidase 2; MTB: Multidisciplinary tumor board; mTOR: mammalian target of rapamycin; MTORC: mammalian target of rapamycin complex; NetSarc: French Sarcoma Network; OS: overall survival; OUTC'S: National observatory for the off-label use of targeted therapies in sarcomas; PDGFR: Platelet-derived growth factor receptor; PFS: progression-free survival; PI3K: phosphoinositide-3-kinase; PR: partial response; RANK/RANKL/OPG: Receptor activator of NF-KappaB / Receptor activator of NF-KappaB ligand / osteoprotegerin protein; RB: Retinoblastoma protein; RECIST: Response Evaluation Criteria for Solid Tumors; RET: rearranged during transfection proto-oncogene; SD: stable disease; SHH/GLI: Sonic Hedgehog; TKI: tyrosine kinase inhibitors; T: targeted therapy; VEGFR: Vascular endothelial growth factor receptor.

\section{Competing interests}

The manuscript was financially supported by Pfizer (France). 


\section{Authors' contributions}

MPP participated in the analysis of data, interpretation of data, drafting and revision of the manuscript. IRC participated in the acquisition of funding, conceived the study, participated in its design, supervision, in the acquisition and interpretation of data and in the revision of the manuscript. JL participated in the analysis and interpretation of data, and drafting of the manuscript. MG and LB participated in the collection, management and analysis of data, and the coordination and of the study. MR participated in the collection and analysis of data, the coordination and supervision of the study, and drafting and revision of the manuscript. NC, NEW, LB, JD, CL, SPN, $H P, J O B, J C G, A T, L C, B N$ and $H C$ participated in the collection and interpretation of data and to revision of the manuscript. JYB conceived the study, participated to its design, and to the acquisition and interpretation of data. PMB participated in the collection and interpretation of data, drafting and revision of the manuscript. All authors read and approved the final version of the manuscript.

\section{Acknowledgement}

We acknowledge the Clinical Research Associates of every center who participated on the collection of data. The manuscript was financially supported by grants from Pfizer (Paris, France), and by grants from the Institut National du Cancer (NetSarc, INTERSARC).

\section{Author details}

'Department of Pediatric Oncology, Léon Bérard Cancer Center, 28, rue Laennec, 69008 Lyon, France. ²Université Claude Bernard Lyon 1, Lyon, France. ${ }^{3}$ Hôpital Mère-enfant, 7 quai Moncousu, Nantes, France. ${ }^{4} \mathrm{CHU}$ Hautepierre, 1 avenue Molière, Strasbourg, France. ${ }^{5}$ Institut Gustave Roussy, 114 Rue Edouard Vaillant, Villejuif, France. ${ }^{6}$ Centre Oscar Lambret, 3 rue Frédéric Combemale, Lille, France. ${ }^{7}$ Institut Curie, 26 rue d'Ulm, Paris, France. ${ }^{8}$ Centre Jean Perrin, 58 Rue Montalembert, Clermont-Ferrand, France. ${ }^{9} \mathrm{CHU}$ La Timone, 264 rue Saint-Pierre, Marseille, France. ${ }^{10} \mathrm{Centre}$ Antoine Lacassagne, 33 Avenue Valombrose, Nice, France. ${ }^{11} \mathrm{CHU}$ Jean Minjoz, 2 Bd Fleming, Besançon, France. ${ }^{12} \mathrm{CHU}$ Bretonneau, 2 Bd Tonnellé, Tours, France. ${ }^{13} \mathrm{CHU}$ Raymond Poincaré, 104 Bd Raymond Poincaré, Garches, France.

Received: 1 July 2015 Accepted: 1 November 2015 Published online: 05 November 2015

\section{References}

1. Clinical E, Guidelines P. Bone sarcomas: ESMO Clinical Practice Guidelines for diagnosis, treatment and follow-up. Ann Oncol. 2014;25 Suppl 3(Supplement 3):iii113-23.

2. Ferrari S, Smeland S, Mercuri M, Bertoni F, Longhi A, Ruggieri $P$, et al. Neoadjuvant chemotherapy with high-dose Ifosfamide, high-dose methotrexate, cisplatin, and doxorubicin for patients with localized osteosarcoma of the extremity: a joint study by the Italian and Scandinavian Sarcoma Groups. J Clin Oncol. 2005;23:8845-52.

3. Kager L, Zoubek A, Pötschger U, Kastner U, Flege S, Kempf-Bielack B, et al. Primary metastatic osteosarcoma: presentation and outcome of patients treated on neoadjuvant Cooperative Osteosarcoma Study Group protocols. J Clin Oncol. 2003;21:2011-8.

4. Bacci G, Briccoli A, Longhi A, Ferrari S, Mercuri M, Faggioli F, et al. Treatment and outcome of recurrent osteosarcoma: experience at Rizzoli in 235 patients initially treated with neoadjuvant chemotherapy. Acta Oncol. 2005;44:748-55.

5. Ferrari S, Briccoli A, Mercuri M, Bertoni F, Picci P, Tienghi A, et al. Postrelapse survival in osteosarcoma of the extremities: prognostic factors for long-term survival. J Clin Oncol. 2003;21:710-5.

6. Kleinerman ES, Gano JB, Johnston DA, Benjamin RS, Jaffe N. Efficacy of liposomal muramyl tripeptide (CGP 19835A) in the treatment of relapsed osteosarcoma. Am J Clin Oncol. 1995;18:93-9.

7. Fagioli F. High-dose chemotherapy in the treatment of relapsed osteosarcoma: an Italian sarcoma group study. J Clin Oncol. 2002;20:2150-6.

8. Laverdiere C, Kolb EA, Supko JG, Gorlick R, Meyers PA, Maki RG, et al. Phase II study of ecteinascidin 743 in heavily pretreated patients with recurrent osteosarcoma. Cancer. 2003;98:832-40.

9. Berger M, Grignani G, Giostra A, Ferrari S, Ferraresi V, Tamburini A, et al. 153Samarium-EDTMP administration followed by hematopoietic stem cell support for bone metastases in osteosarcoma patients. Ann Oncol. 2012;23:1899-905.
10. Meyers PA, Schwartz CL, Krailo MD, Healey JH, Bernstein ML, Betcher D, et al. Osteosarcoma: the addition of muramyl tripeptide to chemotherapy improves overall survival-a report from the Children's Oncology Group. J Clin Oncol. 2008;26:633-8

11. Kempf-Bielack B, Bielack SS, Jürgens H, Branscheid D, Berdel WE, Exner GU, et al. Osteosarcoma relapse after combined modality therapy: an analysis of unselected patients in the Cooperative Osteosarcoma Study Group (COSS). J Clin Oncol. 2005;23:559-68.

12. Gaspar N, Di Giannatale A, Geoerger B, Redini F, Corradini N, Enz-Werle N, et al. Bone sarcomas: from biology to targeted therapies. Sarcoma. 2012;2012:301975.

13. Eberst L, Cropet C, Le Cesne A, Pautier P, Penel N, Adenis A, et al. The off-label use of targeted therapies in sarcomas: the OUTC'S program. BMC Cancer. 2014;14:870.

14. NetSarc - Accueil https://netsarc.sarcomabcb.org/home.htm

15. Imaging Response Criteria - Cancer Imaging Program - National Cancer Institute http://imaging.cancer.gov/clinicaltrials/imaging

16. CTCAE Files http://evs.nci.nih.gov/ftp1/CTCAE/About.htm

17. Forscher C, Mita M, Figlin R. Targeted therapy for sarcomas. Biologics. 2014:8:91-105.

18. Vemulapalli S, Mita A, Alvarado Y, Sankhala K, Mita M. The emerging role of mammalian target of rapamycin inhibitors in the treatment of sarcomas. Target Oncol. 2011;6:29-39.

19. Wan X, Mendoza A, Khanna C, Helman LJ. Rapamycin inhibits ezrinmediated metastatic behavior in a murine model of osteosarcoma. Cancer Res. 2005:65:2406-11.

20. Chawla SP, Staddon AP, Baker LH, Schuetze SM, Tolcher AW, D'Amato GZ, et al. Phase II study of the mammalian target of rapamycin inhibitor ridaforolimus in patients with advanced bone and soft tissue sarcomas. J Clin Oncol. 2012;30:78-84

21. Schuetze SM, Zhao L, Chugh R, Thomas DG, Lucas DR, Metko G, et al. Results of a phase II study of sirolimus and cyclophosphamide in patients with advanced sarcoma. Eur J Cancer. 2012;48:1347-53.

22. Demetri GD, Chawla SP, Ray-Coquard I, Le Cesne A, Staddon AP, Milhem $M M$, et al. Results of an international randomized phase III trial of the mammalian target of rapamycin inhibitor ridaforolimus versus placebo to control metastatic sarcomas in patients after benefit from prior chemotherapy. J Clin Oncol. 2013;31:2485-92.

23. Pignochino $Y$, Grignani G, Cavalloni G, Motta M, Tapparo M, Bruno S, et al, Sorafenib blocks tumour growth, angiogenesis and metastatic potential in preclinical models of osteosarcoma through a mechanism potentially involving the inhibition of ERK1/2, MCL-1 and ezrin pathways. Mol Cancer. 2009:8:118.

24. Maki RG, D'Adamo DR, Keohan ML, Saulle M, Schuetze SM, Undevia SD, et al. Phase II study of sorafenib in patients with metastatic or recurrent sarcomas. J Clin Oncol. 2009:27:3133-40.

25. Grignani G, Palmerini E, Dileo P, Asaftei SD, D’Ambrosio L, Pignochino Y, et al. A phase II trial of sorafenib in relapsed and unresectable high-grade osteosarcoma after failure of standard multimodal therapy: an Italian Sarcoma Group study. Ann Oncol. 2012:23:508-16.

26. Maris JM, Courtright J, Houghton PJ, Morton CL, Kolb EA, Lock R, et al. Initial testing (stage 1) of sunitinib by the pediatric preclinical testing program. Pediatr Blood Cancer. 2008;51:42-8.

27. Dubois SG, Shusterman S, Ingle AM, Ahern CH, Reid JM, Wu B, et al. Phase I and pharmacokinetic study of sunitinib in pediatric patients with refractory solid tumors: a children's oncology group study. Clin Cancer Res. 2011;17:5113-22

28. Mahmood ST, Agresta S, Vigil CE, Zhao X, Han G, D'Amato G, et al. Phase II study of sunitinib malate, a multitargeted tyrosine kinase inhibitor in patients with relapsed or refractory soft tissue sarcomas. Focus on three prevalent histologies: leiomyosarcoma, liposarcoma and malignant fibrous histiocytoma. Int J Cancer. 2011;129:1963-9.

29. Sleijfer S, Ray-Coquard I, Papai Z, Le Cesne A, Scurr M, Schöffski P, et al. Pazopanib, a multikinase angiogenesis inhibitor, in patients with relapsed or refractory advanced soft tissue sarcoma: a phase II study from the European organisation for research and treatment of cancer-soft tissue and bone sarcoma group (EORTC study 620. J Clin Oncol. 2009;27:3126-32.

30. Van der Graaf WTA, Blay J-Y, Chawla SP, Kim D-W, Bui-Nguyen B, Casali PG, et al. Pazopanib for metastatic soft-tissue sarcoma (PALETTE): a randomised, double-blind, placebo-controlled phase 3 trial. Lancet. 2012;379:1879-86.

31. Mross K, Frost A, Steinbild S, Hedbom S, Büchert M, Fasol U, et al. A phase I dose-escalation study of regorafenib (BAY 73-4506), an inhibitor of 
oncogenic, angiogenic, and stromal kinases, in patients with advanced solid tumors. Clin Cancer Res. 2012;18:2658-67.

32. A phase II study evaluating efficacy and safety of Regorafenib in patients with metastatic bone sarcomas https://clinicaltrials.gov/ct2/show/ NCT02389244

33. Van Glabbeke M, Verweij J, Judson I, Nielsen OS. Progression-free rate as the principal end-point for phase II trials in soft-tissue sarcomas. Eur J Cancer. 2002;38:543-9.

34. Bielack SS, Kempf-Bielack B, Branscheid D, Carrle D, Friedel G, Helmke K, et al. Second and subsequent recurrences of osteosarcoma: presentation, treatment, and outcomes of 249 consecutive cooperative osteosarcoma study group patients. J Clin Oncol. 2009;27:557-65.

35. Pignochino Y, Dell'Aglio C, Basiricò M, Capozzi F, Soster M, Marchiò S, et al. The combination of Sorafenib and Everolimus Abrogates MTORC1 and mTORC2 upregulation in osteosarcoma preclinical models. Clin Cancer Res. 2013;19:2117-31

36. Collins M, Wilhelm M, Conyers R, Herschtal A, Whelan J, Bielack S, et al, Benefits and adverse events in younger versus older patients receiving neoadjuvant chemotherapy for osteosarcoma: findings from a meta-analysis. J Clin Oncol. 2013;31:2303-12.

37. Ray-Coquard I, Le Cesne A. A role for maintenance therapy in managing sarcoma. Cancer Treat Rev. 2012;38:368-78.

\section{Submit your next manuscript to BioMed Central and take full advantage of:}

- Convenient online submission

- Thorough peer review

- No space constraints or color figure charges

- Immediate publication on acceptance

- Inclusion in PubMed, CAS, Scopus and Google Scholar

- Research which is freely available for redistribution 